cannot have "always" had an influence, although the current influence is indeed major, largely because its enthusiasts publish endless books and articles telling everyone how to do it. Scally and Donaldson make no mention of the vast areas of medical practice for which the evidence base is small and likely to remain so.

They then discuss learning from complaints and critical incidents to prevent their recurrence. This has not proved easy, but we are told that "clinical governance has the opportunity to address this weakness." How? More complaints, all taking time to investigate, ${ }^{4}$ may indicate greater familiarity with complaining rather than a worsening service. Critical incidents (incidents that can harm) are easy to define, but it is less certain that reducing their number reduces the number of incidents that actually do harm.

\section{Uninspiring idea}

Scally and Donaldson conclude that clinical governance is "a big idea that ... can inspire and enthuse." I know people who think that clinical governance is a small idea, a rehash of all sorts of "management speak" and poorly thought through generalisations that can depress and dishearten. Scally and Donaldson represent clinical governance (their figure "Integrating approaches of clinical governance") as a hexagon, each segment containing some items: for example, in the segment "Coherence" is the item "goals of individual, team, and organisation aligned." Would that alignment were that simple (see figure).

Perhaps the article was rushed into print before Scally and Donaldson could sit back and think hard about it. But that is not acceptable from people of their authority. Clinical governance emerges as a mixture of the blindingly obvious (people should lead well and work well in teams) and the unproved (clinical audit). In recent years, clinicians at the coalface have suffered a succession of Big Ideasachieving a balance, continuing medical education, Calmanisation-based on unimpeachable principles. Each has fallen short because of other factors. ${ }^{5-7}$ Now Scally and Donaldson tell us that clinical governance is the Big Idea that will really work, apparently just by making it a statutory duty. I am sure they are sincere in wanting better quality of care in the NHS. We all want that, though I am bound to ask, by what comparisons is overall quality unsatisfactory? For Scally and Donaldson to convince us that clinical governance will work, they must give us realities not generalisations: a few real problems and their solutions. Then leave us to decide if we are inspired and enthused.

The most important elements in the delivery of quality in health care are contained in the relations between human beings. With good working relations, clinical governance (or whatever it is called) happens naturally; with poor working relations, setting up committees and defining quality on pieces of paper delivers only pieces of paper. If the service providers are measuring their own activity, why should we trust their measurement more than we trust the activity they provide? When all the necessary measuring is done, why should we trust the measurers more than we do the service providers? The inevitable consequence is loss of trust by, whether or not there is loss of trust in, the providers.

This obsession with measurement and accountability is not unique to medicine ${ }^{8}$ and fosters "the illusion that life can be reduced to manipulable numbers, the delusion that something which is said to be so therefore $i$ so." ${ }^{\prime 9}$ The delivery of health care is complicated, so complicated that there are no easy solutions, no curative Big Ideas. There will always be problems and strains within the service. It would have been enough for Scally and Donaldson to have announced the end of the age of competition within the NHS, asked us and allowed us to collaborate for better health care, and given us encouragement: "people work best if they are given a worthwhile job and are allowed to get on with it." ${ }^{10}$

Scally and Donaldson do not convince me that they will spare the emperor's embarrassment.

I thank Chris Johnson for helpful suggestions for the final draft. Competing interests: None declared.

1 Scally G, Donaldson LJ. Clinical governance and the drive for quality improvement in the new NHS in England. BMJ 1998;317:61-5.

2 Oxford English dictionary on compact disc. 2nd ed. Oxford: Oxford Oxford English dictionary
University Press, 1993.

3 Raffle AE, Alden B, Mackenzie EFD. Detection rates for abnormal cervical smears: what are we screening for? Lancet 1995;345:1469-73.

Bamji A. Complaints: time to bite back? BMJ 1993;307:944-5.

5 Miller P. On not achieving a balance. BMJ 1993;306:156-7.

6 Goodman NW. What shall we do about CME? Anaesthesia Points West 1996;29:33-4.

7 Barber P. The colleges, Calman, and the new deal. Lancet 1997;350:974.

8 Power M. The Audit Society: rituals of verification. Oxford: Oxford University Press, 1997:183.

9 Bywater M. Modern management-hunting in yapping packs, half swaggering, half mincing. It hides behind jargon, trying to control what it can't understand. It is the cult of the age. Observer $1998 \mathrm{Jul} \mathrm{19:28,} \mathrm{col} 2$.

10 Owen AV. Getting the best from people. BMJ 1995;310:648-51.

\section{Favourite prayers}

\section{The ship}

What is dying?

I am standing on the sea shore,

a ship sails in the morning breeze

and starts for the ocean.

She is an object of beauty

and I stand watching her

till at last she fades

on the horizon

and someone at my side says:

"She is gone."

Gone! Where?

Gone from my sight-that is all.

She is just as large in the masts, hull and spars as she was when I saw her,

and just as able to bear her load of living

freight to its destination.

The diminished size and total loss of sight is in me, not in her,

and just at the moment when someone at my side says,

"She is gone"

there are others who are watching her coming,

and other voices take up a glad shout:

"There she comes!"

-and that is dying.

Bishop Brent (1862-1926).

From Favourite Prayers compiled by Deborah Cassidi; Cassell, 1998; ISBN 030470315 X, price $£ 9.99$. 